\title{
Moeda, crédito e ciclos econômicos em Marshall`
}

\author{
Sérgio Fornazier Meyrelles Filho \\ Professor - Universidade Federal de Goiás (UFG) \\ Endereço: Campus Samambaia, s/n - Goiânia/GO \\ CEP: 74690-900 - E-mail: fornazier@ufg.br
}

\section{Rogério Arthmar}

Professor Universidade Federal do Espírito Santo (UFES)

Endereço: Av. Fernando Ferrari, 514 - Goiabeiras - Vitória/ES

CEP: 29075-910 - E-mail: rogerio.arthmar@ufes.br

\begin{abstract}
Resumo
Este artigo tem por objetivo examinar os elementos centrais da análise de Alfred Marshall sobre as flutuações cíclicas, contemplando o papel da especulação e do crédito nesse contexto. A primeira seção contém breve introdução ao assunto. A seguir, tratam-se das contribuições de Marshall sobre os determinantes das taxas de juros normal e de mercado, bem como a sua reformulação da Teoria Quantitativa da Moeda. Após, apresenta-se a sua explicação dos ciclos econômicos, na qual se articulam em uma mesma estrutura os elementos teóricos expostos nas seções anteriores. Ao final, uma comparação da teoria monetária de Marshall com as contribuições de Irving Fisher e Knut Wicksell é realizada, destacando-se os pontos de contato, bem como de distanciamento, entre esses proeminentes teóricos neoclássicos dos fenômenos monetários. Elabora-se ainda uma versão dinâmica formal do modelo marshalliano dos ciclos, incluída em apêndice.
\end{abstract}

\section{Palavras-Chave}

Moeda. Crédito. Especulação. Ciclos comerciais.

\begin{abstract}
This paper reviews Alfred Marshall's analysis of commercial cycles and the role of both speculation and credit in the different phases of this process. After a brief introduction to the subject, Marshall's concepts of normal and banking interest rates, as well as his restatement of the Quantity Theory of Money, are discussed. Next, comes his explanation of the business cycles, where the theoretical elements seen in the previous sections are articulated in a single structure. Lastly, Marshall's monetary theory is compared with the contributions by Irving Fisher and Knut Wicksell, highlighting the points of convergence, as well as the ones of disagreement, among these prominent neoclassical monetary theorists. A formal dynamic version of the Marshallian model of business cycles is presented in appendix.
\end{abstract}

\section{Keywords}

Money. Credit. Speculation. Commercial cycles.

\section{JEL Classification}

B22. B26. B30.

Os autores agradecem o apoio do CNPq. 


\section{Introdução}

Nas primeiras décadas do século vinte, os economistas da Escola de Cambridge, dentre os quais Arthur Cecil Pigou, Dennis Holme Robertson e John Maynard Keynes, propuseram distintas explicações acerca dos possíveis mecanismos deflagradores e de propagação dos ciclos econômicos. ${ }^{1}$ Diferenças à parte, tais análises, em notável extensão, adotavam como ponto de partida a estrutura teórica edificada por Alfred Marshall desde fins do século dezenove. Muito embora as contribuições deste último ao desenvolvimento da ciência econômica moderna tendam a ser predominantemente associadas à evolução da teoria marginalista dos preços no plano microeconômico, traços essenciais da análise macroeconômica clássica (na acepção sugerida por Keynes 1996 [1936], cap. 3), podem ser embrionariamente identificados em distintos momentos de sua obra.

O presente artigo confere ênfase à contribuição inovadora de Marshall quanto aos determinantes da demanda por moeda, notadamente o conceito de encaixe monetário em sua relação com a tripla margem de escolha, e a articulação deste fator com as expectativas empresariais e o crédito, elementos analíticos de longa tradição na explicação das flutuações comerciais por parte da economia política britânica. Marshall, em verdade, desempenhou papel fundamental na continuidade do pensamento monetário clássico, ao mesmo tempo em que descortinava novos horizontes analíticos para seus seguidores em Cambridge ao qualificar em diversos aspectos a interação entre os setores real e monetário da economia, dicotomia analítica herdada de seus predecessores. ${ }^{2}$ No que segue, consideram-se inicialmente os postulados de Marshall acerca da natureza das taxas de juros, bem como o seu entendimento peculiar da Teoria Quantitativa da Moeda como base de determinação do nível geral dos preços. Nas duas seções seguintes do trabalho discutem-se, respectivamente, suas ideias sobre os juros e os preços em geral para, em seguida, voltar-se

1 Para as teorias dos ciclos da Escola de Cambridge no período indicado, consulte-se, por exemplo, Laidler (1999, caps. 4-6), Bigg (1990, caps. 10, 11), Bridel (1987, caps. 4-7) e Eshag (1965, caps. III, IV).

2 Ao tratar da contribuição de Marshall ao desenvolvimento da teoria monetária no final do século dezenove, Laidler observa que, à época, o economista britânico já havia "produzido o que equivale a um protótipo para diversas análises pré-keynesianas do ciclo comercial" (Laidler, 1990, p. 61). Eshag, da mesma forma, ressalta não apenas o débito teórico de Marshall com seus predecessores clássicos no tocante à moeda e aos ciclos, mas também o fato de que nenhum de seus sucessores logrou escapar completamente da influência do mestre (Eshag, 1965, p. 89-110). Para uma avaliação do legado teórico e profissional de Marshall à economia em geral, veja-se Groenewegen (1995, cap. 20) e Stigler (1990). 
a atenção à sua análise dos ciclos comerciais. A última seção estabelece uma comparação entre as visões monetária de Marshall e de seus contemporâneos Irving Fisher e Knut Wickell, destacando-se não somente os aspectos comuns, mas também as diferenças entre as perspectivas destes autores. Em apêndice, introduz-se ainda uma versão dinâmica formal da concepção dos ciclos de Marshall.

\section{A teoria marshalliana dos juros e do capital}

De acordo com Marshall, a taxa de juros poderia ser definida simultaneamente de duas formas complementares: por um lado, como uma "recompensa pela espera" enquanto, por outro, ela seria o preço pago pelo uso do capital. Na verdade, essa dupla definição nos remete diretamente a uma aplicação particular, para o mercado de capital, de uma concepção mais geral acerca do processo social de produção da riqueza, baseada nos postulados da utilidade e da produtividade marginais. Sobre esses princípios ergue-se a análise marshalliana da oferta e da demanda, conceitos aplicáveis tanto às mercadorias em si quanto aos fatores de produção, resultando, nesse último caso, uma teoria da distribuição (Bridel, 1987, p. 8-15).

Os elementos incorporáveis ao processo produtivo, para Marshall, seriam considerados como fatores de produção, enquanto o princípio da substituição garantiria que, dado o estado das artes, tais fatores pudessem ser combinados em diferentes proporções para produzir um mesmo bem. Desse modo, assumida uma conduta maximizadora por parte das firmas, os fatores produtivos seriam demandados em quantidades inversamente relacionadas à remuneração dos seus serviços sob a vigência de rendimentos marginais decrescentes. Por outro lado, os proprietários de tais recursos estariam interessados em ofertá-los em quantidades diretamente proporcionais aos seus respectivos preços. Ao flutuarem de forma a conciliar a oferta e a demanda, as remunerações dos fatores produtivos assegurariam, em última instância, que a economia caminhasse rumo a uma situação de plena utilização da capacidade produtiva.

O capital real, definido como um conjunto de bens incorporáveis à produção, encontrar-se-ia, portanto, sujeito à lógica descrita. Nesse sentido, a taxa de juros representaria o preço pago (ou recebido) 
pelos serviços do capital. Como explica Marshall nos seus Principles of Economics (doravante Principles):

A taxa de juros é determinada, a longo prazo, pelas duas séries de forças da oferta e da procura, respectivamente. [...] Assim, o juro, sendo o preço pago pelo uso de capital em qualquer mercado, tende a um nível de equilíbrio tal que a procura total de capital nesse mercado, a essa taxa de juros, seja igual à oferta total que haja ali a essa taxa. (Marshall, 1977 [1890], p. 443)

Na passagem acima, evidencia-se um aspecto crucial da visão marshalliana sobre o funcionamento da economia, qual seja, a admissão de existência de uma taxa de juros de equilíbrio que tenderia a garantir, no correr do tempo, o pleno emprego dos fatores de produção. Vejamos então, com maior detalhe, as questões relacionadas a esse ponto. Marshall estava ciente que uma teoria dos juros precisaria levar em conta tanto a demanda agregada por capital quanto o estoque existente do mesmo na economia. A concorrência, por sua vez, em situação de equilíbrio, asseguraria o estabelecimento de uma taxa uniforme de retorno sobre todo o capital em uso. Marshall sabia também, contudo, que raciocinar dessa forma, no contexto da abordagem marginalista, significava incorrer em um argumento circular, pois o valor das diversas quantidades de capital não poderia ser definido independentemente do sistema de preços e vice-versa. ${ }^{3}$

Diante desse quadro, a solução por ele contemplada compreendeu uma distinção entre os diferentes tipos de capital. Por um lado, haveria o capital já investido (specialized capital), materializado em usos concretos e considerado, portanto, como um estoque. Por outro, existiria o que ele denominou de capital livre, definido como um conjunto de recursos reais ainda não comprometido com qualquer uso particular (free capital), estando, portanto, disponível para investimento em uma variedade de aplicações, constituindo, mais propriamente, um fluxo (Eshag, 1965, p. 46).

3 A questão originaria a famosa controvérsia do capital, na década de 1960, a respeito da qual se pode consultar, por exemplo, Harcourt e Lang (1978, p. 31-105, 173-240) e Garegnani (2012). 
Os rendimentos derivados do estoque de capital especializado seriam concebidos como uma quase-renda e dependeriam, basicamente, do nível de salários (supondo a existência de apenas dois fatores de produção) e da demanda pelos produtos de cada equipamento particular. A taxa de juros, propriamente dita, seria determinada no mercado de capital livre, a partir da intersecção entre a função demanda por novos investimentos e a oferta de poupanças disponíveis. Procurava assim Marshall evitar eventuais embaraços teóricos derivados da noção de estoque de capital. $\mathrm{O}$ trecho a seguir ilustra o argumento descrito:

Mas aqui o principal obstáculo resulta do fato de que o rendimento derivado do capital já investido em determinadas coisas, como fábricas ou navios, é propriamente uma quase-renda, e só pode ser considerado como juro na presunção de que o valor do capital da inversão tenha permanecido inalterado. (Marshall, 1977 [1890], p. 443)

Já em Money, Credit and Commerce, a definição encontra-se mais elaborada:

A taxa de juros dos empréstimos de longo prazo é regulada, de um lado, pelas necessidades de capital por parte dos negócios para conduzir os empreendimentos que têm em vista e, de outro, pela quantidade de capital que não se encontra especializada ou "fixa" em algum uso particular. Essa quantidade é, com efeito, o excesso da produção agregada recente sobre o consumo de riqueza correspondente, juntamente com a quantidade de nova riqueza já dedicada a usos produtivos, mas ainda não especializada de forma definitiva em nenhum deles. (Marshall, 1929 [1923], p. 255)

Convém, então, explicitar as principais forças operantes no mercado de capital livre. O lado da oferta, como mencionado, estaria conceitualmente identificado com a disponibilidade de poupanças, passadas ou presentes, para investimentos. De acordo com Marshall 
(1929 [1923], p. 275-82), o volume de poupança, num dado período, dependeria de diversos fatores, alguns deles de caráter não estritamente econômico por natureza. Dentre esses, mereceriam destaque o costume, os hábitos de autocontrole e de antevisão do futuro, a segurança acerca das condições sociais e políticas e, sobretudo, o altruísmo associado à força do sentimento familiar.

A poupança, no entanto, dependeria também de duas variáveis econômicas cruciais, a saber, o nível de renda e a taxa de juros. Com relação à primeira delas, Marshall assinala nos Principles que a "capacidade de poupar depende de que se tenha um excedente de renda sobre os gastos necessários, excedente que é, naturalmente, maior entre os mais ricos" (Marshall, 1977 [1890], p. 282). Haveria, portanto, uma relação direta entre o nível de renda e a disposição a poupar e, uma vez que todos os demais fatores permanecessem constantes, quanto maior o nível de renda da economia, maior a sua capacidade de poupança e de acumulação. Como nota Eshag (1965, p. 50), ao tratar dessa relação funcional específica, Marshall teria em mente de forma precípua as mudanças seculares na magnitude da produção e da renda ou, ainda, o crescimento de longo prazo da riqueza, e não as suas variações cíclicas. Seja como for, no que diz respeito ao segundo fator econômico mencionado, embora Marshall acreditasse que em algumas situações pudesse mesmo se verificar uma relação inversa entre taxa de juros e poupança, como regra geral, quanto maior a primeira, maior a segunda.

Mas, embora a poupança em geral seja afetada por muitas causas além da taxa de juros, e esta pouco influencie a poupança de muita gente; $e$ enquanto alguns poucos, que tenham resolvido assegurar um rendimento de um montante fixo para si próprios ou para suas famílias, cheguem mesmo a economizar menos com uma elevada taxa do que com uma reduzida taxa de juros; não obstante isso, a balança pende favoravelmente à opinião de que um acréscimo na taxa de juros, ou preço da procura da poupança, tende a aumentar o volume da mesma. (Marshall, 1977 [1890], p. 443) 
A relação descrita estaria diretamente associada à definição de taxa de juros como uma recompensa pela espera. Parece mais razoável aceitar, todavia, que Marshall e os economistas marginalistas, de forma geral, não considerassem a elasticidade-juros da oferta de capital como fator decisivo no processo de ajustamento da economia, o qual seria exercido prioritariamente pela demanda. De acordo com Bridel:

[E]les [os autores marginalistas] viram corretamente a relação investimento-taxa de juros como o elemento crucial no processo de ajustamento entre a poupança e o investimento. Independentemente do grau de inelasticidade ou da forma bizarra que a função poupança pudesse ter em relação à taxa de juros, ela não teria influência decisiva na tendência à plena utilização do volume de recursos para investimento tornados disponíveis pelo próprio processo de poupança. (Bridel, 1987, p. 18)

A demanda por capital livre, isto é, por recursos para investimento num determinado momento, estaria, segundo Marshall, intimamente relacionada ao que ele identificava como "a extensão e a riqueza do campo para o investimento de capital", ou ainda, "da rentabilidade dos negócios" (Reisman, 1987, p. 41). Conforme Eshag (1965, p. 52), essa noção de lucratividade, sobre a qual se baseia a análise marshalliana da demanda agregada por investimentos, é um tanto vaga e não leva a uma definição precisa. Afigura-se lícito pensar aqui, contudo, em termos de uma espécie de variável expectacional, que refletiria o sentimento da comunidade empresarial em relação às perspectivas presentes e futuras de retorno sobre o capital, ou seja, "as previsões de lucros elevados a serem obtidos no desenvolvimento de novas ou mesmo antigas indústrias" (Marshall, 1929 [1923], p. 258). Esse estado de expectativas, por sua vez, dependeria de uma série de fatores, como listados na "Lei da demanda por capital", formulada originalmente por Marshall e sua esposa Mary Paley Marshall em Economics of Industry (1879):

A demanda por capital cresce com cada aumento nos números da população, nos recursos naturais do país, na eficiência das artes de produção e no escopo que essas artes proporcionam ao emprego de capital auxiliar e à 
durabilidade do capital fixo. A taxa de juros à qual o capital pode encontrar emprego num país com uma dada população industrial em cada estado das artes de produção depende da quantidade de capital oferecida para empréstimo. (Marshall e Marshall, 1994 [1879], p. 124)

Definido esse quadro, quanto maior o preço pelo uso do capital, isto é, a taxa de juros, menor a demanda pelos serviços do mesmo, assumindo-se um comportamento maximizador por parte dos agentes econômicos. Ainda, uma redução da taxa de juros poderia tornar viável, na mente do empresário, uma série de investimentos com perspectivas de retorno até então inferiores ao custo do capital. Existiria, portanto, uma relação inversa entre a demanda por recursos disponíveis para investimento e a taxa de juros, a qual desempenha papel crucial na análise do crédito elaborada por Marshall.

A interação entre as curvas de demanda e oferta de capital não especializado determinaria uma taxa de juros de equilíbrio, também denominada taxa "normal" de juros. Em torno desse valor flutuaria a taxa efetiva de juros, chamada alternativamente taxa de "mercado" ou "monetária". ${ }^{4}$ Essa última, por sua vez, sendo resultante da oferta e demanda de capital na forma de empréstimos, encontrarse-ia sujeita a perturbações de curto prazo, fazendo-a oscilar em torno do seu centro de gravidade, a taxa normal de juros. No longo prazo, todavia, a taxa monetária tenderia a refletir a demanda e a oferta de capital expressas em termos reais, ou seja, haveria um movimento de convergência para uma situação de equilíbrio em que a versão monetária dos juros terminaria por replicar a sua versão real. Quando assim ocorresse, inexistiriam recursos desempregados ou ociosos de forma involuntária na economia. ${ }^{5}$ Eventuais diferenças entre o investimento e a poupança de pleno emprego seriam corrigidas, principalmente, por meio de uma variação no nível de investimento induzida pelas variações na taxa de juros de mercado. Como explicado em Economics of Industry: "A taxa de juros está em

4 É importante ressaltar que a distinção analítica entre uma taxa de juros de equilíbrio, definida por condicionantes reais, e uma taxa de mercado, associada às condições monetárias da economia e ao comportamento do crédito bancário, foi originalmente proposta por Henry Thornton (1991 [1802]) ao discutir as possíveis consequências do papel-moeda inconversível em reservas metálicas durante as Guerras Napoleônicas.

5 Bridel (1987) examina, de forma pormenorizada, esse aspecto da teoria em conexão com a visão de Marshall sobre os ciclos. 
equilíbrio quando ela permite que a oferta total de capital [livre, na forma de poupança] possa encontrar emprego" (Marshall e Marshall, 1994 [1879], p. 124).

Nesse contexto, as modificações na disponibilidade de moeda resultariam incapazes de exercer influência duradoura sobre os aspectos e motivações reais da economia, sendo a taxa normal de juros, portanto, independente dos eventos puramente monetários. Embora as variações na oferta de moeda pudessem produzir divergências de curta duração entre as taxas de juros monetária e normal, movimentos cumulativos nos preços e na demanda por empréstimos tenderiam a promover um retorno à condição de equilíbrio. Como ressaltado por Reisman: "A moeda, para Marshall, é potente no curto prazo, mas impotente no longo prazo no que tange ao seu impacto sobre a taxa de juros" (1987, p. 263). Ou, ainda, segundo o próprio Marshall, ao comentar as consequências de uma expansão monetária derivada de um ingresso extraordinário de ouro no país sob o regime de conversibilidade, em depoimento a Royal Comission on the Value of Gold and Silver (1887-1888): "A taxa média de desconto é afetada permanentemente pela lucratividade dos negócios. Tudo que o influxo de ouro faz é gerar uma espécie de ondas concêntricas na superfície da água" (Marshall, 1926, p. 40). A seguir, analisam-se os aspectos da teoria monetária marshalliana relacionados à determinação do nível de preços.

\section{A versão cash-balance da Teoria Quantitativa}

Para Marshall, o valor da moeda, assim como o de todas as mercadorias, seria determinado a partir das leis da oferta e da demanda, tanto no curto como no longo prazo. Adepto confesso da Teoria Quantitativa da Moeda, ele, todavia, atribuía limites à versão tradicional da mesma, notadamente no tocante às variações de preços no curto prazo. ${ }^{6}$ Assim, a certa altura de Money, Credit and Commerce, lê-se:

6 Isso, contudo, não impediu Marshall, em determinados momentos, de fazer uso dessa versão, notadamente para explicar as variações de preço em períodos longos (veja-se Bigg, 1990, p. 18-20 e Eshag, 1965, p. 4-6). 
O valor total de dinheiro de um país, multiplicado pelo número médio de vezes que ele troca de mãos com fins de negócios a cada ano é, obviamente, igual ao total de negócios realizados naquele país por pagamentos diretos em dinheiro durante aquele ano. Mas essa proposição de identidade não mostra as causas que governam a rapidez de circulação da moeda [...]. Esta "Doutrina Quantitativa" é útil apenas até aí. Ela não indica, porém, quais são as "outras coisas" que devem ser assumidas constantes a fim de justificar tal proposição, e ela não explica as causas que governam a "rapidez de circulação" (Marshall, 1929 [1923], p. 43). ${ }^{7}$

Diante do que julgava ser uma fraqueza da versão clássica da Teoria Quantitativa, Marshall propunha uma abordagem alternativa, que ficaria conhecida como versão Cambridge ou cash-balance. Sua ideia central era incorporar explicitamente uma teoria da demanda por moeda no âmbito da análise monetária, o que, dentre outras coisas, permitiria analisar-se com maior propriedade as flutuações de preços associadas às oscilações no estado de confiança do público com relação ao curso dos negócios. Se, por um lado, Marshall entendia que os motivos que regulam a velocidade de circulação não seriam óbvios, por outro, ele assinalou igualmente que "as mudanças na rapidez de circulação da moeda são elas próprias relacionadas às alterações na quantidade de poder de compra imediato que o povo de um país pensa ser vantajoso manter em mãos" (Marshall, 1929 [1923], p. 43).

Neste ponto, é importante destacar duas questões fundamentais a respeito do tema em pauta. Em primeiro lugar, a concepção clássica de que o custo de produção determinaria, em última instância, o valor da moeda, seria inteiramente abandonada por Marshall. Assim, a aplicabilidade da Teoria Quantitativa estaria assegurada tanto no curto quanto no longo prazo. Em segundo lugar, ao tratar da determinação do nível de preços por meio da versão cash-balance, Marshall tinha em mente estoques e não fluxos. Diferentemente do que acontecia com a análise clássica, em que os preços flutuavam

\footnotetext{
7 Esse tipo de crítica à teoria clássica dificilmente seria aceitável com relação aos trabalhos de autores como John Stuart Mill e, sobretudo, Henry Thornton. Confira-se, por exemplo, Mill (1996 [1848], v. II, p. 104) e Thornton (1991 [1802], p. 96-97), bem como Meyrelles Filho e Arthmar (2011, p. 164-169) e, ainda, Andrade e Lopes (1989, p. 75-78).
} 
de forma a compatibilizar um fluxo de bens (oferta) com um fluxo de despesas monetárias (demanda), agora estariam contrapostos o estoque de moeda e a demanda por esse mesmo estoque. $\mathrm{O}$ valor da moeda deveria, então, conciliar essas duas magnitudes (Bridel, 1987, p. 27). Essa abordagem parece se encontrar em plena sintonia com a opção marshalliana de privilegiar uma análise da demanda por saldos monetários em detrimento da noção de velocidade de circulação (Laidler, 1991, p. 53-54). Vejamos então como seriam determinadas a demanda e a oferta de moeda sob tais condições.

No que diz respeito à oferta monetária, Marshall, em certo sentido, adota posição bastante próxima da ortodoxia clássica. Como regra geral, o termo moeda (ou dinheiro), em sentido estrito, seria aplicado às moedas metálicas (de ouro ou prata) e às notas bancárias conversíveis em espécie (Eshag, 1965, p. 8). Isso, contudo, não significaria ignorar-se a existência de substitutos para a moeda, dentre os quais os mais importantes seriam os cheques e, em alguns casos, as letras de câmbio, e muito menos a importância desses instrumentos como meios facilitadores das transações. O próprio Marshall anota a esse respeito:

O valor total do dinheiro requerido pelos negócios da Inglaterra é, obviamente, relativamente pequeno, pois as classes médias e altas pagam suas obrigações com cheques a apenas fração diminuta desses cheques é apresentada para conversão em dinheiro. Em sua maior parte, eles simplesmente transferem comando sobre poder de compra de uma conta bancária para outra. (Marshall, 1929 [1923], p. 46)

Outros autores marshallianos, como Pigou (1927) e Robertson (1926), iriam ainda mais longe, reconhecendo, explicitamente, o crédito como parte da oferta monetária. Em todo caso, para Marshall, os cheques e os instrumentos de crédito, de forma geral, desde que circulassem livremente e despertassem a devida confiança no ambiente dos negócios, deveriam ter influência sobre os preços semelhante àquela exercida pela moeda propriamente dita, na medida em que também representariam poder de compra sobre as mercadorias disponíveis. Sua análise da determinação do valor da moeda, porém, parte do pressuposto de existência de uma estrita proporcionalidade 
tanto entre o volume de moedas metálicas e o volume de notas conversíveis, como entre o volume dessas últimas e o total de crédito. Em última instância, o estoque de poder de compra da economia, num dado período, estaria determinado pela oferta de metais preciosos, notadamente no regime de padrão-ouro tradicional. Como destacado por Bridel: "Assim, no sistema monetário conhecido por Marshall, a análise do valor da moeda podia ser conduzida em termos de ouro sem violentar em demasia as realidades do cotidiano" (Bridel, 1987, p. 27).

Uma importante implicação desse tipo de abordagem refere-se ao fato de que a oferta de moeda é concebida como uma variável exógena, representada, em termos gráficos, por uma linha reta vertical proporcional ao estoque de ouro monetário, ou seja, inelástica com relação ao nível de preços (Marshall, 1929 [1923], p. 283). É necessário lembrar, em tais condições, que esse estoque de reservas áureas seria determinado pelo livre funcionamento do comércio internacional, como sugerido pelos economistas clássicos (Laidler, 1991, p. 50-52). A moeda, no entendimento de Marshall, poderia então ser definida como um meio para se atingir dada finalidade. Ela não seria demandada primordialmente por si mesma, mas por representar capacidade aquisitiva absoluta ao seu detentor: "A moeda não é desejada apenas como tal, mas porque a sua posse proporciona comanda imediato de poder de compra geral numa forma conveniente" (Marshall, 1929 [1923], p. 38). Em outras palavras, a moeda seria desejada por representar liquidez imediata.

Mas, por qual razão o público haveria de manifestar necessidade de tal natureza? De acordo com Marshall, por dois motivos básicos, a saber: para a realização de transações e por precaução. Com relação ao primeiro motivo, é importante ter presente que, na concepção marshalliana, o dinheiro seria, acima de tudo, um meio facilitador das transações econômicas, tal como acreditavam os autores clássicos. Diferentemente dos bens materiais específicos, a posse de dinheiro possibilitaria a satisfação imediata das mais variadas necessidades cotidianas, bem como a realização de compras no momento certo e em condições favoráveis. O motivo precaução, por sua vez, corresponderia à demanda por liquidez para fazer frente às contingências e às oportunidades de efetuar compras vantajosas, ou seja, para aproveitar os preços em baixa quando os mercados se encontrassem deprimidos (Marshall, 1929 [1923], p. 227). 
Estreitamente associada à demanda de tipo "precaucional" encontrase a noção de hoarding, ou seja, a acumulação de moeda na forma de entesouramento. Dada a existência de claros incentivos para a liquidez, as pessoas desejariam manter uma determinada parcela de sua renda na forma de moeda (cash-balance). Isso, entretanto, implicaria um custo de oportunidade equivalente aos benefícios que poderiam advir da aplicação de tais recursos em usos alternativos. Nesse sentido, cada indivíduo, dada sua racionalidade, deveria definir a sua demanda por saldos monetários ponderando as vantagens associadas à três usos possíveis (threefold margin), a saber: (i) a posse da liquidez absoluta; (ii) a aquisição de bens de consumo, ou (iii) a aplicação em uma máquina capaz de assegurar certa renda monetária. De acordo com Marshall:

Mas o dinheiro em mãos não fornece rendimento; portanto, todos devem pesar (de forma mais ou menos automática e instintiva) os benefícios oriundos de uma ampliação do estoque de dinheiro vivo contra aqueles que conseguiria investindo parte desse valor numa mercadoria - por exemplo, um casaco ou um piano - da qual derivaria um benefício direto, ou ainda, em uma fábrica ou uma ação em bolsa, que lhe proporcionariam uma renda pecuniária. (Marshall, 1929 [1923], p. 38-39)

A proporção dos seus recursos que os membros de uma comunidade estariam dispostos a manter na forma monetária dependeria também, decisivamente, de fatores como a extensão do sistema de crédito, os meios de transporte e de produção, bem como das instituições econômicas em geral, que conformariam, num dado momento, os "hábitos prevalecentes dos negócios". Uma vez estabelecida a demanda pelo estoque existente de moeda como proporção da renda, podemos então apreender mais facilmente o argumento subjacente à versão cash balance da Teoria Quantitativa com o auxílio de uma versão estilizada do que se convencionou denominar Equação de Cambridge, na qual o encaixe monetário surge na forma de uma variável dependente de outros fatores, como explicitado a seguir: ${ }^{8}$

8 A qual, contudo, não chegou a ser explicitamente apresentada por Marshall. Versões formais da equação de trocas de Cambridge foram elaboradas, contudo, por Pigou (1917) e Keynes (1923, chap. 3). 


$$
M=k[u(e, c, i), z] P Y
$$

onde

$M=$ oferta monetária (estoque)

$k=$ encaixe monetário

$P=$ nível geral de preços $\quad Y=$ renda real $u=$ função utilidade

$e=$ liquidez $\quad c=$ consumo na margem $\quad i=$ taxa efetiva de juros

$z=$ fatores institucionais.

No lado direito da Equação (1) encontramos os fatores determinantes da demanda por moeda. Se a renda real e o coeficiente ficam inalterados, o valor da moeda e, portanto, o nível de preços, deve guardar relação proporcional às variações da oferta monetária . Ou ainda, nos termos de Marshall: "se tudo o mais permanece constante, existe então uma relação direta entre o volume de dinheiro e o nível de preços de modo que se um é aumentado em dez por cento, o outro será aumentado em dez por cento" (Marshall, 1929 [1923], p. 45). Fica evidente que a validade da Teoria Quantitativa, na sua versão marshalliana, depende da estabilidade de uma série de fatores que dificilmente permaneceriam inertes ao longo do tempo, a saber, a preferência pela liquidez, o consumo e a taxa monetária de juros , além dos hábitos institucionais dos negócios , como será tratado a seguir.

\section{O processo cumulativo dos preços e o ciclo comercial}

No mesmo contexto em que trata da Teoria Quantitativa da Moeda, Marshall ressalta que os fatores a serem considerados constantes para a validade da relação proporcional entre a oferta monetária e os preços, isto é, os determinantes do encaixa monetário, estavam, em verdade, sujeitos a oscilações:

Essa relação entre o volume de dinheiro e o nível geral dos preços pode ser alterada de forma permanente por mudanças, primeiro, na população e na riqueza, o que modifica a renda 
agregada; segundo, pelo crescimento das instituições de crédito, que substituem o dinheiro por outros meios de pagamento; terceiro, pelas alterações nos métodos de transporte, produção $e$ dos negócios em geral [...] e ainda ser modificada temporariamente por flutuações na confiança geral no mundo do comércio e na própria atividade. (Marshall, 1929 [1923], p. 45)

As oscilações no estado de confiança estariam associadas, sobretudo, aos movimentos cíclicos da economia, em conexão com a chamada "lei do entesouramento" (law of hoarding), expressando o fato de que os encaixes de moeda dos particulares aumentariam durante a deflação e diminuiriam nos períodos inflacionários. Como descrito por Marshall em seu depoimento a Royal Comission: "[...] a demanda por um metal com o propósito de entesouramento aumenta com a elevação de seu valor e diminui com a sua queda contínua, pois as pessoas que entesouram acreditam que aquilo que está aumentando de valor provavelmente seguirá no mesmo curso e vice-versa" (Marshall, 1926, p. 6). Essa proposição geral permite estabelecer uma clara conexão entre o valor da moeda e a confiança nela depositada pelo público. Ela representa uma via a partir da qual se poderia conceber uma elevação do nível de preços mais do que proporcional às variações da oferta monetária, ${ }^{9}$ na medida em que a confiança na moeda fosse abalada por uma contínua queda em seu valor (Marshall, 1929 [1923], p. 47-48). Após todos os possíveis elementos perturbadores haverem se dissipado, porém, uma modificação na quantidade de moeda seria capaz tão somente de causar uma variação proporcional no nível de preços. Esse resultado teórico é apresentado por Marshall a partir de uma espécie de processo cumulativo, no qual ele procura integrar a sua concepção sobre os juros à teoria da determinação do nível de preços.

Partindo-se de uma situação de equilíbrio, em que a taxa de juros de mercado fosse igual à taxa de equilíbrio, Marshall supõe que a oferta monetária seria expandida por um influxo de ouro no sistema bancário. Na medida em que as reservas bancárias fossem acrescidas, tais instituições estariam mais propensas a expandir os seus emprés-

9 Esse talvez seja o grande elemento de evolução da versão Cambridge em relação à versão clássica da Teoria Quantitativa, ou seja, incorporar explicitamente a possibilidade de que as variações de preço fossem não proporcionais às variações na oferta monetária. 
timos, dada a existência de uma relação de proporcionalidade entre o nível de reservas e suas operações de crédito. Isso, por sua vez, provocaria uma queda da taxa de juros de mercado, estimulando a procura por empréstimos até que esta última igualasse a oferta ampliada de crédito. Quando o processo houvesse se completado, haveria um maior comando sobre capital real nas mãos dos especuladores, sem que tivesse se verificado efetivamente um aumento do capital disponível real (Dardi e Galegatti, 1992).

De posse desse dinheiro adicional, os especuladores dirigir-se-iam ao mercado como compradores e terminariam por fazer com que os preços se elevassem. A inflação resultante representaria estímulo adicional à especulação, na medida em que ela alimentaria expectativas de novos aumentos futuros nos preços. Desse modo, a demanda por empréstimos seria novamente expandida, ocasionando aumento subsequente de preços, o que aguçaria ainda mais os especuladores, e assim por diante: "Os empréstimos a um indivíduo fazem dele um bom consumidor para outros a preços atrativos, tornando-os, portanto, igualmente desejosos de recorrer ao crédito, o que faz deles bons consumidores, e assim o movimento cresce" (Marshall, 1929 [1923], p. 257).

À medida que a demanda por empréstimos e os preços aumentassem gradualmente, dois movimentos inter-relacionados teriam lugar. Primeiramente, a inflação dos preços domésticos impactaria os termos do comércio com o exterior, apreciando a taxa real de câmbio e afetando negativamente a balança comercial, ocasionando, por conseguinte, redução das reservas em ouro dos bancos, que se tornariam então relutantes em continuar expandindo seus empréstimos. Em tais condições, a taxa de juros de mercado terminaria por ser elevada, e esse movimento de transmissão entre preços e juros continuaria até o ponto em que a taxa bancária novamente se alinhasse à taxa de juros normal ou de equilíbrio, que permanecera inalterada.

Os ciclos comerciais, entretanto, poderiam ter origem também em alterações na própria taxa de juros normal, como resultado de modificações no estado de confiança da comunidade empresarial quanto à lucratividade atual ou prospectiva dos negócios. O impulso inicial para tanto poderia advir de fatores diversos, como guerras, rumores ou simplesmente mediante a superação espontânea de um estado de desconfiança decorrente de infortúnios anteriores. Com frequência, 
um movimento cíclico seria deflagrado pela ocorrência de oscilações imprevistas nas colheitas (Marshall e Marshall, 1994 [1879], p.152). No caso específico de uma safra abundante, por exemplo, os preços dos gêneros agrícolas seriam reduzidos e, ao passo que menos dinheiro fosse necessário para adquiri-los, restariam mais recursos para serem gastos com os demais bens. No entanto, e isso é importante ter em mente, qualquer que fosse a causa inicial, a fase ascendente do ciclo teria como ponto de partida uma elevação da demanda por mercadorias, ocasionada pelo que se poderia chamar de um renascimento da confiança (revival of confidence). Após o impulso inicial, o otimismo crescente na prosperidade dos negócios tomaria forma em um processo cumulativo de expansão do crédito e de majoração dos preços e das rendas nominais, juntamente com a intensificação das atividades especulativas. Conforme a descrição oferecida por Marshall:

Os produtores percebem que a demanda por seus bens encontra-se em alta; eles esperam vender com lucro e estão dispostos a pagar bons preços pela pronta entrega do que querem. Os empregadores competem uns com os outros por trabalho; os salários sobem; e os empregados, ao gastarem seus salários, acrescem a demanda por todos os tipos de mercadorias. Novas companhias, públicas ou privadas, são criadas [...] e assim o desejo de comprar e a disposição de pagar preços majorados crescem em conjunto; o crédito é exultante, e facilmente aceita promessas escritas de pagamento. Preços, salários e lucros seguem em elevação: verifica-se elevação geral das rendas dos que se dedicam ao comércio; eles gastam livremente, aumentam a demanda por bens $e$ fazem os preços subir ainda mais. Muitos especuladores, testemunhando isso, e pensado que a situação continuará, adquirem artigos com a expectativa de vendê-los com lucro (Marshall e Marshall, 1994 [1879], p. 152; veja-se também Marshall, 1929 [1923], p. 249).

Esse movimento de reajuste dos preços e dos rendimentos seria reforçado ainda por três importantes forças de propagação. A primeira estaria relacionada ao comportamento da demanda por moeda du- 
rante o ciclo. De acordo com a "lei do entesouramento" mencionada anteriormente, numa fase de preços ascendentes o público apresentaria tendência a diminuir os seus encaixes monetários. À medida que assim sucedesse, teria lugar pressão adicional sobre a elevação cumulativa de preços. A segunda força a impulsionar o processo inflacionário residiria na incapacidade de a taxa monetária de juros acompanhar a alta de preços. Essa relativa rigidez faria com que os empréstimos se tornassem gradativamente mais baratos em termos reais, o que estimularia ainda mais a bolha de crédito. A terceira força estaria relacionada a outro tipo de rigidez relativa, qual seja, a dos preços das matérias-primas e, sobretudo, dos salários: "Quando os preços se encontram em ascensão, o aumento nos preços dos bens finais é geralmente mais rápido do que o das matérias-primas e sempre mais rápido do que o da remuneração do trabalho" (Marshall e Marshall, 1994 [1879], p. 156; Marshall, 1977 [1890], p. 590-591).

A defasagem nos reajustes dos diferentes preços permitiria assim um aumento temporário dos lucros, exacerbando ainda mais a fase ascendente do ciclo. A euforia típica da fase de prosperidade prosseguiria sustentada por um volume cada vez maior de crédito disponibilizado pelos bancos: "Firmas antigas tomam emprestado para ampliar os seus negócios; novas firmas, com a finalidade de começar suas atividades, enquanto os especuladores se endividam para comprar e estocar bens" (Marshall e Marshall, 1994 [1879], p. 152). Dois tipos de especuladores são identificados pelo Marshall nesse contexto. Os primeiros, os ditos especuladores profissionais, constituiriam um grupo de indivíduos sagazes e bem informado sobre as condições gerais dos negócios e não apenas se distinguiriam como, em certa extensão, lucrariam às custas do segundo grupo de especuladores, os ditos amadores, comumente desinformados e impulsivos em suas ações. $^{10}$

Marshall adverte que, no entanto, chegaria o momento em que certos indivíduos passariam a perceber que a continuidade do processo de expansão no crédito e reajuste nos preços seria insustentável. Os credores estariam entre os primeiros a vislumbrar o sinal dos tempos, cogitando a contração de seus empréstimos. Mas, à medida que isso viesse a acontecer, uma série de empreendimentos iniciados

${ }^{10}$ Em um manuscrito, muito provavelmente datado do final do século dezenove, Marshall anotou: "Os especuladores profissionais diferem muito uns dos outros por seus recursos e amplitude dos riscos que assumem. Mas os métodos de cada um deles encontram-se em acentuado contraste com os utilizados pelos especuladores profissionais" (apud Dardi e Galegatti, 1992, p. 587). 
durante a fase de expansão e ainda inconclusos se defrontariam com sérias dificuldades. A taxa de juros de mercado começaria a sofrer elevação e alguns especuladores, perante a dificuldade em honrar suas dívidas, reduziriam seus estoques de mercadorias, o que tenderia a estancar o ímpeto do aumento dos preços. Esse movimento de ajuste, por sua vez, deixaria outros especuladores apreensivos, os quais decidiriam igualmente se desfazer dos seus estoques: os preços então passariam a cair. Não demoraria até que um grande especulador falisse, seguido por outros em sua esteira. A confiança teria cedido lugar à desconfiança e, progressivamente, ao pânico. A economia ingressaria na fase descendente do ciclo, caracterizada por um movimento cumulativo de contração do crédito e de redução dos preços e dos rendimentos, conformando uma típica crise comercial: "A desconfiança cresce, aqueles que emprestaram tornam-se ansiosos para recuperar seus créditos e recusam-se a renovar os empréstimos em quaisquer condições [...] quebras e pânico semeiam pânico e quebras. A tempestade comercial deixa o seu rastro carregado de ruínas" (Marshall e Marshall, 1994 [1879], p. 153).

A situação resultante, que aos incautos pareceria uma crise de superprodução, refletiria, na verdade, explica Marshall, um estado de desorganização do comércio, originado por uma crise de confiança. Os mesmos fatores que outrora estimulavam a bonança agora agravariam a tormenta. "Quando os preços estão em queda, a retração no preço dos bens finais é geralmente mais rápida do que nos preços das matérias-primas, e sempre mais rápido do que na recompensa do trabalho" (Marshall e Marshall, 1994 [1879], p. 156). Finda a tormenta, vigoraria um estado de calmaria, mas impregnado de desconfiança. Aqueles que houvessem escapado à calamidade não estariam dispostos a se aventurar facilmente; o crédito seguiria escasso e novos empreendimentos deixariam de ser iniciados. Essa situação perduraria até se verificar a plena restauração do estado de confiança dos agentes econômicos (revival of confidence), quando a economia seria reconduzida então, eventualmente, e como que por uma mão invisível, a uma nova fase ascendente.

Eis, portanto, em linhas gerais, a essência da análise marshalliana do ciclo econômico. Com relação a essa teoria, três aspectos devem ser destacados. Em primeiro lugar, seu ponto de partida, obviamente, é a análise clássica, notadamente a teoria do ciclo de crédito de John Stuart Mill em que elementos como o estado de confiança, a especu- 
lação, o comportamento da demanda por moeda e o crédito ocupam lugar central (veja-se, Mill, 1996 [1848], v. II, caps. XI-XII, XXIXXIV; Forget, 1990). Aliás, o legado da economia política clássica é notório nas diversas áreas da obra de Marshall, excetuando-se a sua teoria do valor. A distinção entre uma taxa monetária e uma taxa de juros de equilíbrio determinada em termos reais, bem como a Teoria Quantitativa da Moeda, são partes dessa herança. ${ }^{11}$ Marshall, no entanto, possui o mérito de desenvolver e sistematizar essa análise.

Um segundo aspecto a ser destacado aqui se refere ao fato de Marshall não possuir uma concepção estritamente monetária das oscilações comerciais, como ressaltado por Laidler (1990, p. 61): "[N]ão se deve atribuir a Marshall uma 'teoria monetária' do ciclo no sentido de haver ele tratado flutuações exógenas na quantidade de moeda como impulsos decisivos na deflagração das flutuações cíclicas". Apesar de não apontar, de forma exclusiva, um ou outro elemento causal como primordial no início dos ciclos comerciais, Marshall defendia a ideia de que eles teriam sempre uma causa real, tal como um choque de oferta, uma guerra, ou um fenômeno do gênero.

Por fim, chegamos ao terceiro aspecto já referido: existe, na obra de Marshall, uma clara tensão entre, de um lado, as leis gerais do valor e da distribuição e, de outro, a teoria do ciclo. ${ }^{12} \mathrm{Ou}$ seja, entre as suas análises de curto e de longo prazo. Nesse sentido, como destacado por Bridel: "O ciclo comercial de Marshall é uma mera lista descritiva de imperfeições que limitam, no curto prazo, a tendência da economia rumo à condição de equilíbrio competitivo de pleno-emprego" (Bridel, 1987, p. 48). Cabe notar nesse contexto que, em Marshall, o estudo das flutuações não se apresenta, explícita e sistematicamente, integrado a uma análise do comportamento das variáveis poupança e investimento durante o ciclo. A noção de que as flutuações de curto prazo poderiam exercer influência sobre a posição de equilíbrio

${ }^{11}$ David Ricardo no panfleto The high price of bullion (1810), adota claramente a dicotomia entre as taxas de juros já, como visto, antecipada por Henry Thornton: "É apenas durante o intervalo em que as emissões do Banco afetam os preços que devemos nos preocupar com a abundância de dinheiro; a taxa de juros, durante esse tempo, encontra-se abaixo de seu nível natural; mas tão logo a soma adicional de notas ou dinheiro seja absorvida na circulação geral, a taxa de juros volta a se elevar" (Works III, 2004, p. 91).

12 Nesse sentido, conforme descrito por Bigg (1990, p. 187-188): "Embora Marshall admitisse a possibilidade de falhas temporárias de demanda efetiva em situações de depressão, tal era vista enquanto ocorrência efêmera. [...] A análise de longo prazo proposta por Marshall era amplamente 'Clássica', atada aos conceitos da análise marginal e ao [seu] esquema substantivamente racional." 
de longo prazo do sistema econômico seria progressivamente incorporada pelos pupilos de Marshall, particularmente Pigou (1924, 1967 [1927]) e Robertson (1932 [1926], 1948 [1915]), no âmbito da análise marshalliana, com base no desenvolvimento da abordagem a qual se convencionou chamar de análise poupança-investimento das flutuações cíclicas, bem como mediante o conceito de poupança forçada. ${ }^{13}$

\section{Marshall e seus contemporâneos: Fisher e Wicksell}

A Teoria Quantitativa da Moeda, ao final do século dezenove e início do século vinte, foi objeto de reformulações teóricas substanciais por diversos economistas contemporâneos de Marshall, destacandose o norte-americano Irving Fisher e o sueco Knut Wicksell. Breve comparação entre a contribuição desses autores à teoria monetária da época será relevante no sentido de se avaliar os progressos analíticos, assim como os limites, das reflexões econômicas ancoradas na Teoria Quantitativa da Moeda a partir das diferentes perspectivas adotadas por tais autores.

Em sua obra mais célebre, The Purchasing Power of Money (1911), Fisher busca reconstruir teoricamente a relação entre a oferta monetária e o nível geral de preços, realçando diversos aspectos de tal conexão que a economia clássica deixara obscuro em sua análise do tema. Para tanto, parte ele da equação de trocas ampliada

$$
M V+M^{\prime} V^{\prime}=P T
$$

em que $P$ é o nível geral de preços, $M$ é o estoque de moeda tangível, ou seja, moedas de ouro e notas conversíveis em poder do público, $V$ é a velocidade de circulação desse estoque, $M^{\prime}$ representa o total de depósitos bancários, $V^{\prime}$ é sua a respectiva velocidade de circulação e $T$ indica o volume físico de transações (Fisher, 1920 [1911], p. 53). Em geral, de acordo com Fisher, o total de depósitos bancários guardaria relação fixa com o estoque de moeda em circulação para dadas condições de desenvolvimento industrial e da civilização.

\footnotetext{
${ }^{13}$ Sobre o desenvolvimento da análise poupança-investimento em Cambridge, no período situado entre as duas guerras mundiais, consulte-se Bridel (1987) e Eshag (1965).
} 
Para Fisher, fatores reais explicariam o volume de transações no longo prazo, tais como distribuição geográfica dos recursos naturais, o grau vigente de divisão do trabalho, a dimensão do estoque de capital, bem como o nível de desenvolvimento das técnicas de produção. Além disso, as preferências dos consumidores, o grau de liberdade do comércio, as facilidades de transporte, as características do sistema bancário e o estado de confiança nos negócios atuariam igualmente no dimensionamento do comércio na economia. Já a velocidade de circulação tanto da moeda tangível quanto dos depósitos bancários dependeria primordialmente dos hábitos individuais de poupança e entesouramento, da difusão do uso de cheques, da regularidade do sistema de pagamentos da comunidade, assim como da densidade populacional e da rapidez do transporte (Fisher, 1920 [1911], p. 74-89).

Posto que o volume de comércio e a velocidade de circulação da moeda no agregado estariam regidos por fatores independentes das demais variáveis da equação de trocas, Fisher explica os movimentos no nível geral de preços como resultantes das variações no estoque de moeda, incluindo os depósitos bancários. Isso porque a velocidade de circulação da moeda estaria adaptada ao que os hábitos e a conveniência haveriam provado ser útil aos indivíduos, enquanto o volume de comércio responderia à disponibilidade de recursos naturais e à eficiência de seu uso, a oferta monetária sendo impotente para afetar as condições gerais de produção. Assim, após argumentar que mudanças em $M$ produzem alterações proporcionais em $M^{\prime}$ sem modificar permanentemente $V, V^{\prime}$ e $T$, Fisher reafirma a conclusão clássica de que a variável final de ajuste de uma alteração no estoque de moeda seria o nível geral de preços (Fisher, 1920 [1911], p. 149-183).

A versão de Fisher do modus operandi do ajuste nos preços, contudo, nada tem de mecânica, envolvendo um processo de transição com efeitos temporários das mudanças no estoque de moeda sobre as demais variáveis da equação de trocas. À medida que os preços aumentam em decorrência de uma maior disponibilidade de ouro monetário, por exemplo, a lucratividade das empresas cresce, mesmo que seus custos não financeiros sejam remarcados na mesma proporção. Isso ocorre por conta do retardo no avanço da taxa de juros nominal, que induz os empresários a se endividarem ainda mais durante a fase de prosperidade na busca de ampliarem a sua produção e os lucros. Desse modo, os depósitos bancários $M^{\prime}$ como proporção do estoque 
de moeda $M$, assim como o volume de comércio $T$, registram aumento durante a fase ascendente dos preços.

O boom prossegue até que a taxa de juros seja finalmente reajustada não só na medida da inflação, mas até mesmo além dela, em função da limitação das reservas bancárias e da redução no valor de garantias dos empréstimos, como os títulos públicos. Teria início assim a fase reversa do ciclo econômico, em que o crédito ficaria mais caro, os lucros se reduziriam, os empréstimos sofreriam contração e os preços entrariam em declínio, com queda, inclusive, da velocidade de circulação da moeda em virtude da relutância dos agentes em se desfazer do dinheiro escasso. Ao longo do tempo, as variáveis da equação de trocas encontrar-se-iam em estado de permanente ajuste, à semelhança de um navio em meio as ondas. Ou, conforme Fisher: "Como os períodos de transição são a regra e os de equilíbrio a exceção, o mecanismo de trocas encontra-se sempre em condição dinâmica, em vez de estática" (Fisher, 1920 [1911], p. 71).

Wicksell, de sua parte, particularmente nos livros Interest and Prices (1898) e no segundo volume de suas Lectures on Political Economy (1906), propõe uma interpretação particular da Teoria Quantitativa da Moeda, na qual a relação estoque de moeda e nível de preços dependeria do regime monetário específico. Numa economia de moeda pura, sem bancos ou depósitos, todas as transações seriam conduzidas por meio da moeda metálica e a velocidade de circulação da moeda, ou sua recíproca, o seu intervalo de descanso (rest), dependeria da regularidade dos pagamentos dos negócios, das reservas para desembolsos imprevistos e da eventual posse de largas quantias devido à venda de blocos de capital. Em termos gerais, Wicksell entende a velocidade média de circulação da moeda constante em tais condições. Os preços, por sua vez, dependeriam do nível desejado do encaixe monetário real dos indivíduos. Em presença de uma ampliação na oferta de ouro, por exemplo, o encaixe-monetário superaria o nível desejado, o excesso seria gasto e os preços terminariam majorados na proporção do estoque acrescido de moeda (Wicksell, 1936 [1898], p. 51-59).

Diferentemente de Fisher, Wicksell considera os depósitos bancários equivalentes a um aumento na velocidade de circulação da moeda tangível, uma vez que a realização de pagamentos mediante transferências escriturais permitiria uma redução no encaixe-monetário real 
dos indivíduos. No limite, em um sistema bancário desenvolvido, a velocidade da circulação da moeda, na forma de notas conversíveis ou ouro cunhado, tenderia ao infinito, e seu efeito seria idêntico a um aumento no estoque de moeda. A diferença parece apenas retórica, mas revela-se funcional para Wicksell elaborar a sua teoria do processo cumulativo numa economia de crédito puro com base numa versão original da Teoria Quantitativa da Moeda.

A dicotomia básica de Wicksell compreende a distinção entre as taxas de juros monetária ou de mercado, isto é, aquela efetivamente cobrada pelos bancos em seus empréstimos, e a taxa dita real ou natural, considerada neutra em relação ao nível de preços e a qual seria estabelecida livremente entre os agentes econômicos no caso de uma economia não monetária ou de trocas puras (Wicksell, 1936 [1898], p. 102-105). Em suas Lectures, Wicksell define a taxa natural como aquela em que "a demanda por capital de empréstimo e a oferta de poupança coincidem exatamente" (Wicksell, 1978 [1915], p. 193). A partir dessa definição, Wicksell concebe um modelo de economia constituída por empreendedores, que contratam os fatores de produção e produzem para a venda; pelos trabalhadores; pelos bancos, que emprestam os recursos dos capitalistas aos empreendedores e, por fim, pelos capitalistas, entendidos aqui como detentores do capital, e que compram bens dos empreendedores para os revenderem aos trabalhadores. Servindo-se de outras hipóteses adicionais, como a uniformidade do período de produção e acumulação nula de capital, Wicksell mostra que quando a taxa natural de juros se eleva acima da taxa de mercado, os empreendedores buscam maior volume de capital junto aos bancos, que tendem a manter inalterada a sua taxa de juros, expandindo o crédito para além da poupança disponível a fim de suprir a demanda adicional. O acréscimo na demanda por mão de obra eleva os salários e, consequentemente, a procura por bens de consumo, aumentando os preços em geral. Como custos e receitas são reajustados na mesma proporção, a lucratividade dos empreendedores permanecerá inalterada e eles continuarão tomando novos empréstimos, mas em maior volume, gerando nova rodada de expansão do crédito e dos preços.

Num sistema de padrão-ouro, o aumento no encaixe monetário nominal dos indivíduos induzido pelos preços em elevação reduz as reservas bancárias até o ponto em que os bancos são forçados a reajustar a sua taxa de juros ao nível da taxa natural, cessando então o 
processo inflacionário. Enquanto a diferença entre as taxas de juros persistir, a inflação continua inabalada, conformando o que Wicksell denominou "processo cumulativo". Ao comentar as diferenças entre os preços relativos, que se moveriam como um pêndulo em direção ao seu valor de equilíbrio, e os preços nominais, Wicksell anotou:

Uma figura análoga para os preços monetários deve ser um objeto móvel, como um cilindro, descansando sobre plano horizontal em posição de dito equilíbrio neutro. A superfície sendo áspera, certa força é necessária para colocar o preço-cilindro em movimento e mantê-lo assim. Enquanto essa força - a elevação ou queda da taxa de juros - permanece em operação, o cilindro continua a se mover na mesma direção. (Wicksell, 1936 [1898], p. 101)

Com base nesse ligeiro esboço das teorias monetárias de Fisher e Wicksell, torna-se possível traçarem-se alguns paralelos com a teoria monetária de Marshall. Primeiramente, é importante notar que, diferentemente do que se observa nas análises tanto de Fisher quanto de Wicksell, a Teoria Quantitativa da Moeda, em sua versão marshalliana dos saldos de caixa, desenvolve-se primordialmente na forma de uma teoria acerca dos determinantes da demanda agregada por moeda, em vez de se apresentar como uma teoria dos preços ou do comportamento da taxa de inflação. Nesse contexto, Marshall desenvolve uma abordagem da problemática monetária que contempla como um de seus elementos essenciais a demanda especulativa por moeda, ideia cara à economia política britânica, mas mencionada apenas ocasionalmente por Fisher e Wicksell. Fisher menciona a demanda por moeda para transações, enquanto Wicksell aproxima-se da noção de demanda por moeda para precaução, mas ambos deixam a desejar no tocante ao componente especulativo da procura por liquidez. Além disso, Fisher parece ter sido o único a englobar os depósitos bancários como parte ativa da oferta monetária, enquanto Marshall e Wicksell mantiveram-se apegados à definição dessa variável como restrita ao ouro metálico e as notas conversíveis, ou a moeda tangível em circulação. Os resultados teóricos, contudo, não chegaram a se diferenciar totalmente por conta dessa distinção. 
Mais importante, certamente, é o fato de que Fisher entendia o sentido de causalidade como estritamente definido da moeda para os preços, enquanto Marshall e Wicksell aceitavam a possibilidade de causação reversa, ou seja, de preços em elevação por causas reais ou imaginárias gerando maior demanda por crédito. Por fim, cabe ressaltar que apesar das diferenças de perspectiva, as abordagens teóricas de Marshall, Wicksell e Fisher admitiam a possibilidade de efeitos de curto prazo das variações da oferta monetária sobre o produto e a velocidade de circulação da moeda em suas respectivas análises dos mecanismos de transmissão das variações na oferta monetária sobre os preços. Tal dinâmica apoiava-se na discrepância temporária entre a taxa de juros cobrada pelos bancos e aquela de caráter real, refletindo as condições efetivas de produção da economia, sendo esse um dos traços distintivos da teoria neoclássica das flutuações econômicas, ainda que com sólidas raízes no pensamento clássico. ${ }^{14}$

\section{Considerações finais}

No plano de análise da economia em seu conjunto, Marshall, seguindo a tradição clássica de Thornton, Ricardo e Stuart Mill, trabalhava com uma clivagem fundamental entre as esferas real e monetária da economia. No âmbito das transações reais, importava a disponibilidade efetiva de bens, o capital livre, como materialização da poupança dos indivíduos, a qual deveria atender uma procura de fatores para investimento, de modo que entre esses dois polos do mercado formar-se-ia certa taxa de juros normal capaz de conciliar os planos de todos os envolvidos. Enquanto o arranjo monetário existente, ou seja, o sistema bancário assentado num regime de padrão-ouro, reproduzisse as condições prevalecentes na economia real, o sistema operaria em situação de equilíbrio, expandindo-se de forma harmoniosa de acordo com o crescimento no estoque de capital permitido pelas poupanças prévias.

A fragilidade inerente da economia originava-se, porém, de uma parte, na relativa autonomia dos bancos, os quais detinham o poder de fixar a taxa de juros efetiva em valores distintos da dita taxa normal, e de outra, no caráter instável das expectativas dos

\footnotetext{
${ }^{14}$ Para elementos teóricos adicionais na comparação entre as abordagens monetárias de Marshall, Wickselle Fisher, consulte-se Boianovsky (2013), Humphrey (1997) eLaidler (1991, caps. 3e5).
} 
investidores, sujeitos a interpretarem os sinais provenientes da esfera monetária como manifestações fidedignas dos fenômenos sucedidos na economia real. Assim, o legado de Marshall para seus sucessores compreendia elementos teóricos fundamentais que, de uma forma ou outra, integrariam as teorias dos ciclos e da demanda efetiva desenvolvidas em Cambridge nas primeiras décadas do século vinte. Mais especificamente, as ideias essenciais de sua análise monetária utilizadas por seus sucessores envolviam, primeiramente, uma elaborada teoria da demanda por moeda e dos encaixes monetários; o papel dominante das oscilações de crédito na dinâmica das crises comerciais; a importância da psicologia dos empreendedores na evolução geral dos negócios; a interdependência entre as distintas atividades econômicas durante os episódios de prosperidade e recessão, e, finalmente, os efeitos distributivos das defasagens nas alterações dos preços e dos custos de produção ao longo das diferentes etapas do ciclo econômico.

\section{Apêndice}

\section{A dinâmica dos ciclos comerciais em um modelo marshalliano}

A teoria dos ciclos comerciais proposta por Marshall pode ser apresentada de modo dinâmico por meio do seguinte modelo formal. Seja $q$ a taxa de juros monetária, definida pelos bancos, e $n$ a taxa normal de juros que garante o equilíbrio entre a oferta e a demanda por capital livre na economia, aqui representadas por curvas de poupança e de investimento, respectivamente, $S(q)$ e $I(q)$, para $S_{q}$ $>0$ e $I_{q}<0$. Seja $p$ o nível geral de preços e $\pi$ a taxa esperada de inflação. Para efeito deste exercício de formalização, por conveniência, assume-se que os agentes formam expectativas quanto ao comportamento futuro da taxa de inflação segundo um padrão adaptativo vis-à-vis o comportamento prévio observado da variável.

Assume-se também que o nível de preços obedeça à Teoria Quantitativa da Moeda, isto é, $p=m(v / y)$, em que $m$ representa a oferta monetária num regime de padrão-ouro, $v$ é a velocidade de circulação da moeda e $y$ é o produto agregado da economia, sendo a proporção entre $v$ e $y$ suposta constante ao longo do ciclo comercial (a título de simplificação, adota-se aqui $v / y=1$ ). 
No tocante à oferta monetária, admite-se que a moeda em poder do público seja nula, de modo que $m=S(q)+m^{\prime}$ indica o total de depósitos à vista, compreendendo a poupança efetuada pelo público $S(q)$ mais $m^{\prime}$ ou o crédito líquido oferecido pelo setor bancário. Por fim, o quociente $\dot{p} / p$ é a taxa efetiva de inflação. Postula-se ainda que o reajuste da taxa de juros monetária pelos bancos encontra-se regido pelo afastamento dos preços de seu patamar de equilíbrio $\bar{p}$ , dado que uma redução no poder de compra da moeda gera evasão de ouro para o exterior e queda no lastro metálico dos bancos, base última de sua oferta de crédito. ${ }^{15}$ A partir dessas especificações, a demanda total por capital livre, que determina $m^{\prime}$ e, via a fórmula da Teoria Quantitativa, os preços, depende linearmente de três fatores:

(i) do diferencial entre as taxas de juros normal e efetiva $(n-q)$, medida da atratividade dos empréstimos; quando $n=q$, a oferta de crédito restringe-se à poupança disponível no sistema bancário e que iguala a procura de recursos para investimento, ou seja, $S(q)=I(q)$, e, por conseguinte, $m^{\prime}=0$; quando $n>q$, $I(q)>S(q)$ e o crédito líquido é positivo, ou seja, $m^{\prime}=(I-S)>0$;

(ii) do afastamento dos preços $p$ de seu nível de equilíbrio $p^{*}$, diferencial que afeta o comportamento dos especuladores profissionais, estimulando-os a vender quando os preços se distanciam demasiadamente de seus valores de equilíbrio, e a comprar na situação oposta, e

(iii) da taxa esperada de inflação $\pi$, que determina a procura especulativa de crédito por parte dos investidores inexperientes.

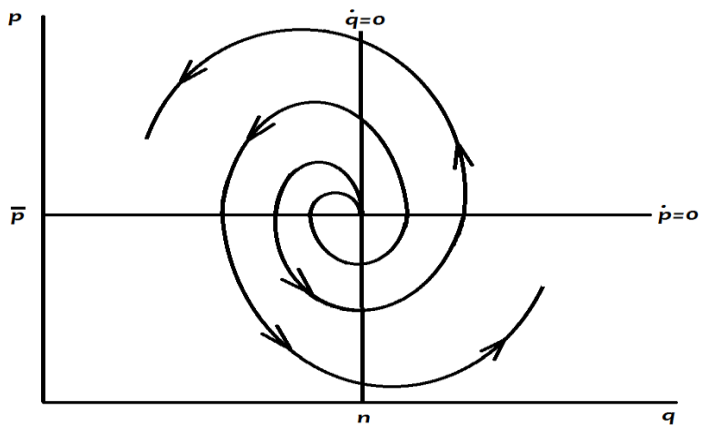

Figura 1. Modelo marshalliano dos ciclos com expectativas adaptativas (foco instável)

${ }_{15}$ Para uma análise formal do funcionamento do sistema clássico de padrão-ouro, consulte-se Barro (1985). 
Com essas especificações, o modelo marshalliano dos ciclos assume a forma abaixo, no qual (Al) descreve os determinantes da taxa efetiva de inflação, influenciada pela diferença entre as taxas normal e monetária de juros $\alpha(n-q)$, assim como pela especulação profissional $\beta\left(p^{*}-p\right.$ e a amadora $\gamma \pi$, esta última baseada puramente nas expectativas; a Equação (A2) explica as variações na taxa efetiva de juros $q$ com base nos efeitos do nível de preços $p$ sobre as reservas áureas dos bancos e o custo do crédito, enquanto (A3) descreve a correção das previsões inflacionárias com base na diferença entre as taxas efetiva e esperada de inflação, ajustada por um fator positivo (expectativas adaptativas).

$$
\begin{array}{lll}
\dot{p}=\left[\alpha(n-q)+\beta\left(p^{*}-p\right)+\gamma \pi\right] p & \alpha, \beta, \gamma>0 & \gamma \neq 1 \\
\dot{q}=\delta\left(p^{*}-p\right) & \delta<0 \\
\dot{\pi}=\sigma[(\dot{p} \div p)-\pi] & \sigma>0
\end{array}
$$

A versão linearizada de (A1)-(A3), após a substituição da primeira equação na terceira, com as derivadas parciais calculadas no ponto fixo $q=n, p=p^{*}$ e $\pi=0$ é

$$
\left[\begin{array}{c}
\dot{p} \\
\dot{q} \\
\dot{\pi}
\end{array}\right]=\left[\begin{array}{ccc}
-\beta \bar{p} & -\alpha \bar{p} & \gamma \bar{p} \\
-\delta & 0 & 0 \\
-\sigma \beta & -\alpha \sigma & \sigma(\gamma-1)
\end{array}\right] \cdot\left[\begin{array}{l}
p \\
q \\
\pi
\end{array}\right]
$$

e o sistema (A4) é inerentemente instável, podendo apresentar trajetória divergente cíclica para os preços, a taxa de juros e as previsões inflacionárias (esta última reforçada pela ação especulativa dos indivíduos), ou então registrar ciclos explosivos (figura 1). ${ }^{16}$

\footnotetext{
${ }^{16}$ Os coeficientes da equação característica do sistema linearizado são $a_{0}=1, a_{1}=\beta \bar{p}-\eta(\gamma-1)$, $a_{2}=\alpha \delta-\beta \sigma<0$ e $a_{3}=-\alpha \delta \sigma \bar{p}>0$. Pela Regra de Descartes, a equação característica tem duas raízes reais positivas, independentemente do sinal de $a_{1}$, ou duas raízes complexas com parte real positiva, além de uma raiz real negativa.
} 


\section{Referências}

ANDRADE, Joaquim Pinto de; LOPES, Carlos Magno. Moeda e crédito: a versão “clássica” de Thornton e Mill. In: AMADEO, Edward (Org.). Ensaios sobre economia politica moderna: teoria e história do pensamento econômico. São Paulo: Marco Zero, p. 69-86, 1989.

BARRO, Robert J. Money and the price level under the gold standard. In: B. EICHENGREEN (Ed.). The gold standard in theory and history. New York: Methuen, p. 81-89, 1985.

BIGG, Robert J. Cambridge and the monetary theory of production: the collapse of Marshallian macroeconomics. New York: St. Martin's Press, 1990.

BOIANOVSKY, Mauro. Fisher and Wicksell on money: a reconstructed conversation. European Journal of the History of Economic Thought, v. 20, n.2, p. 206-237, 2013.

BRIDEL, Pascal. Cambridge monetary thought: the development of saving-investment analysis from Marshall to Keynes. New York: St. Martin’s Press, 1987.

DARDI, Marco e GALLEGATI, Mauro. Alfred Marshall on speculation. History of Political Economy, v. 24, n. 2, p. 571-94, 1992.

ESHAG, Eprime. From Marshall to Keynes: an essay on the monetary theory of the Cambridge School. New York: Augustus Kelley, 1965.

FISHER, Irving. The Purchasing power of money. New York: Macmillan, 1920 [1911].

FORGET, Evelyn. John Stuart Mill's business cycles. History of Political Economy, v. 22, n. 4, p. 629-642, 1990.

GAREGNANI, Pierangelo. On the present state of the capital controversy. Cambridge Journal of Economics, v. 36, p. 1417-1432, 2012.

GROENEWEGEN, Peter. A soaring eagle: Alfred Marshall 1842-1924. Aldershot: Edward Elgar, 1995.

HARCOURT, E. C., LANG, N. F. Capital e crescimento econômico. Rio de Janeiro: Interciência, 1978.

HEGELAND, Hugo. The quantity theory of money: a critical study and interpretation and a restatement. New York: Augustus M. Kelley, 1969.

HUMPHREY, Thomas M.. Fisher and Wicksell on the quantity theory. Federal Research Bank of Richmond Economic Quarterly, v. 83, n.4, p. 71-90, 1997.

KEYNES, John Maynard. A tract on monetary reform. London: Macmillan, 1923.

KEYNES, John Maynard. A teoria geral do emprego, do juro e da moeda. São Paulo: Nova Cultural, 1996 [1936].

LAIDLER, David. Alfred Marshall and the development of monetary economics. In: J. WHITAKER (Ed.). Centenary essays on Alfred Marshall. Cambridge: Cambridge University Press, p. 44-77, 1990.

LAIDLER, David. The golden age of the quantity theory. Princeton: Princeton University Press, 1991.

LAIDLER, David. Fabricating the Keynesian revolution: studies of the inter-war literature on money, the cycle, and unemployment. Cambridge: Cambridge University Press, 1999.

MARSHALL, Alfred. Official papers by Alfred Marshall. London: Macmillan, 1926.

MARSHALL, Alfred. Principles of economics: an introductory volume. London: Macmillan Press, 1977 [1890].

MARSHALL, Alfred. Money credit and commerce. London: Macmillan, [1923] 1929.

MARSHALL, Mary Paley e MARSHALL, Alfred. The economics of industry. Bristol: Thoemmes Press, 1994 [1879].

MEYRELLES FILHO, Sérgio F. e ARTHMAR, Rogério. Moeda, liquidez e poupança forçada na economia clássica. Análise Econômica, v. 29, n. 56, p. 153-77, 2011. 
MILL, John Stuart. Princípios de economia política: com algumas de suas aplicações à filosofia social. 2 volumes. São Paulo: Nova Cultural, 1996 [1848].

PIGOU, Arthur C. The Value of Money. The Quarterly Journal of Economics, 32(1), Nov., p. 38-65, 1917.

PIGOU, Arthur C. Correctives of the trade cycle. In: W.T. LAYTON (Ed.). Is unemployment inevitable? London: Macmillan, p. 91-131, 1924.

PIGOU, Arthur C. Industrial fluctuations. London: Frank Cass, 1967 [1927].

REISMAN, David. Alfred Marshall: progress and politics. London: Macmillan, 1987.

RICARDO, David. The high price of bullion. In P. SRAFFA (Ed.). Works, Volume III. 2004.

ROBERTSON, Dennis H. A study of industrial fluctuation: an enquiry into the character and causes of the so-called cyclical movements of trade. London: The London School of Economics and Political Science, 1948 [1915].

ROBERTSON, Dennis H. Banking policy and the price level: an essay in the theory of the trade cycle. London: P.S. King \& Son, 1932 [1926].

SRAFFA, Piero (Ed.). The works and correspondence of David Ricardo [Works]. Indianapolis: Liberty Fund, 2004

STIGLER, George. The place of Marshall's Principles in the development of economics. In: J. WHITAKER (Ed.). Centenary essays on Alfred Marshall. Cambridge: Cambridge University Press, p. $1-13,1990$.

THORNTON, Henry. An enquiry into the nature and effects of the paper credit of Great Britain. London: Allen \& Unwin, 1991 [1802].

WICKSELL, Knut. Interest and prices. A study of the causes regulating the value of money. London: Macmillan, 1936 [1898].

WICKSELL, Knut. Lectures on political economy. Volume two. Money. Fairfield: Augustus M. Kelley, 1978 [tradução da edição de 1915]. 